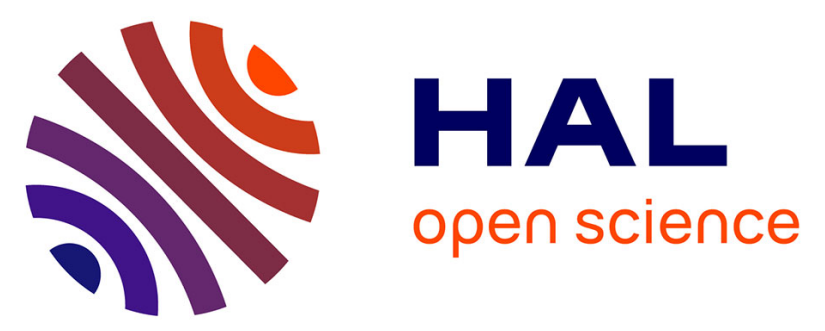

\title{
Size-based characterization of polysaccharides by Taylor dispersion analysis with photochemical oxidation or back scattering interferometry detections
}

L Leclercq, Phoonthawee Saetear, Agnès Rolland-Sabaté, Jean Philippe Biron, Joseph Chamieh, Luca Cipelletti, Darryl J Bornhop, Herve Cottet

\section{To cite this version:}

L Leclercq, Phoonthawee Saetear, Agnès Rolland-Sabaté, Jean Philippe Biron, Joseph Chamieh, et al.. Size-based characterization of polysaccharides by Taylor dispersion analysis with photochemical oxidation or back scattering interferometry detections. Macromolecules, 2019, 52 (12), pp.4421-4431. 10.1021/acs.macromol.9b00605 . hal-03036236

\section{HAL Id: hal-03036236 \\ https://hal.science/hal-03036236}

Submitted on 2 Dec 2020

HAL is a multi-disciplinary open access archive for the deposit and dissemination of scientific research documents, whether they are published or not. The documents may come from teaching and research institutions in France or abroad, or from public or private research centers.
L'archive ouverte pluridisciplinaire HAL, est destinée au dépôt et à la diffusion de documents scientifiques de niveau recherche, publiés ou non, émanant des établissements d'enseignement et de recherche français ou étrangers, des laboratoires publics ou privés. 


\section{Size-based characterization of polysaccharides by Taylor dispersion analysis with photochemical oxidation or back scattering interferometry detections}

Laurent Leclercq ${ }^{1, *}$, Phoonthawee Saetear ${ }^{1,2}$, Agnès Rolland-Sabaté ${ }^{3,4}$, JeanPhilippe Biron ${ }^{1}$, Joseph Chamieh ${ }^{1}$, Luca Cipelletti ${ }^{5}$, Darryl J. Bornhop ${ }^{6,7}$, Hervé Cottet ${ }^{1, *}$

${ }^{1}$ IBMM, Université de Montpellier, CNRS, ENSCM, Montpellier, France

${ }^{2}$ Department of Chemistry and the Center of Excellence for Innovation in Chemistry, Faculty of Science, Mahidol University, Rama 6 Road, Ratchatewi, Bangkok 10400, Thailand

${ }^{3}$ UR1268 Biopolymères Interactions Assemblages, INRA, F-44300 Nantes, France

${ }^{4}$ UMR0408 Sécurité et Qualité des Produits d'Origine Végétale, INRA, Université Avignon, F-84000 Avignon, France

${ }^{5}$ L2C, Université de Montpellier, CNRS, Montpellier, France

${ }^{6}$ Department of Chemistry, Vanderbilt University, Nashville, Tennessee 37235, United States

7 The Vanderbilt Institute for Chemical Biology, Vanderbilt University, Nashville, Tennessee 37235, United States

"Corresponding authors. Tel.: +33 46714 3427; fax: +33 467631046

E-mail addresses: herve.cottet@umontpellier.fr ( $\mathrm{H} . \quad$ Cottet); and laurent.leclercq@umontpellier.fr (L. Leclercq). 


\section{Abstract}

Taylor dispersion analysis (TDA) is a powerful sizing technique very well suited for (macro)molecules between angstrom and sub-micron (typically up to $200 \mathrm{~nm}$ ). However, new detection modes are required for non UV-absorbing (macro)molecules such as most of the polysaccharides, including starches. In this work, two different detection modes were compared, backscattering interferometry (BSI) and UV-photooxidation detection (UV-POD). TDA-BSI measures the relative change of the refractive index (RI) between eluent and sample (water as eluent in this work), whereas TDA-UV-POD detects the UV-absorbing photooxidized products of polysaccharides/starches in a strong alkaline media (130 mM NaOH or $1 \mathrm{M} \mathrm{KOH})$. TDA-UV-POD detection was evaluated for linearity and sensitivity at two wavelengths, $214 \mathrm{~nm}$ and $266 \mathrm{~nm}$. The mass-average hydrodynamic radius $\left(R_{\mathrm{h}}\right)$ obtained by TDA-BSI and TDA-UV-POD was found to be in excellent agreement, while higher average $R_{\mathrm{h}}$ values were obtained by batch dynamic light scattering (DLS) in the same conditions, due to the higher sensitivity of DLS to large size solutes and aggregates. The hydrodynamic radius distributions obtained by TDA and DLS are intrinsically different but both techniques were found to be complementary, providing useful information on sample dispersity. Owing to the absence of the stationary phase, low sample consumption with straightforward sample preparation (no filtration), and no calibration, TDA is anticipated to become a method of choice for the size-based characterization of polysaccharides, including starches. 


\section{Introduction}

Carbohydrates are ubiquitous compounds in the living world since they act as energy and carbon sources which are essential for plant and animal metabolisms ${ }^{1}$. They are also widely used as food additives ${ }^{2,3}$ and in medical applications ${ }^{4,5}$. This class of compounds is of great complexity, namely due to the wide distributions of molar mass $(M)$, chemical composition and branching degree. Different separation techniques can be used for the characterization of polysaccharides. Size-exclusion chromatography $(\mathrm{SEC})^{6}$ is one of the most important technique that can be coupled to one or multiple detection methods such as: differential refractometry $(\mathrm{DRI})^{6,7}$, differential viscosimetry $^{6,8}$ (VISC), multi-angle static light scattering (MALS) ${ }^{9}$. DRI combined to MALS leads to absolute molar mass determination, while the VISC can additionally provide the determination of hydrodynamic radius $\left(R_{h}\right)$ or can be used for universal calibration. More recently, field-flow fractionation (FFF) technologies have been also employed for the separation of high molar mass macromolecules, including polysaccharides ${ }^{10-12}$. Symmetric- or asymmetric-flow FFF ${ }^{13,14}$ has regained interested in the last years, because the absence of a stationary phase in the open channel used in FFF limits the occurrence of undesirable adsorption frequently observed in SEC, especially for high molar mass polymers ${ }^{15-18}$.

Capillary electrophoresis (CE) is also a well suited technique for the analysis of charged and non-charged polysaccharides ${ }^{19}$. However, in CE the previously mentioned detectors used in SEC or in FFF are not available due to the miniaturization of the analysis with online detection. Generally, CE is mostly used with UV, fluorescent, capacitively coupled contactless conductimetry $\left(C^{4} D\right)$ detections and mass spectrometry. Since most of the polysaccharides are not UV or fluorescently responding, derivatization of the analytes are required prior to analysis. However, Rovio et al. described the use of direct UV detection of neutral mono- and 
disaccharides at $270 \mathrm{~nm}$ in beverage $\mathrm{s}^{20}$ and plant fibers ${ }^{21}$, using strong alkaline electrolyte at $\mathrm{pH} 12.6\left(130 \mathrm{mM} \mathrm{NaOH}\right.$ and $\left.36 \mathrm{mM} \mathrm{Na} 2 \mathrm{HPO}_{4} \cdot 2 \mathrm{H}_{2} \mathrm{O}\right)$. Such high $\mathrm{pH}$ ensures the ionization of the (originally neutral) saccharides for CE separation. The detection mechanism was first described as the UV absorbance at $270 \mathrm{~nm}$ of enediolates formed in alkaline conditions. The limits of detection (LOD) for neutral mono- and disaccharides obtained from this method were about $0.02-0.05 \mathrm{mM}^{20}$. However, in later studies, the enediolate proposed structure was disproven by Sarazin et al. ${ }^{22}$ since carbohydrate compounds such as sucrose cannot give enediolate. Alternatively, Sarazin et al. proposed photochemical reaction of carbohydrates in the detection window, induced by UV irradiation and leading to malonaldehyde enolate (also named malondialdehyde, MDA) that is UV absorbing at 265-270 $\mathrm{nm}^{22}$. Later, Oliver et al. ${ }^{23}$, suggested that the photooxidation of the saccharides, and thus their detection, could be enhanced by the application of the electric filed. Schmid et al. ${ }^{24,} 25$ investigated in more details the occurring photochemical reactions using CE-MS and HPLC-MS/MS. Experiments revealed that the conversion reaction of carbohydrate to MDA is sensitive to the residence time under the UV light since MDA can further degrade into non-UV absorbing products $^{24}$. Besides MDA, minor photooxidation reaction products, either with UV absorbing $\left(\mathrm{C}_{4} \mathrm{H}_{6} \mathrm{O}_{2}\right)$ or non-UV absorbing (gluconic acid) compounds could be detected $^{25}$. Photo-initiator Irgacure $\AA^{\circledR} 2959$ added in the background electrolyte could significantly increase sensitivity by $40 \%$ for mono- and disaccharides in CE-UV method, providing LOD of 0.005 to $0.02 \mathrm{mM}$ respectively ${ }^{26}$. This UV photooxidation detection mode (UV-POD) has been applied to the analysis of mono- and disaccharides in a variety of samples such as plant fibers in complex mixtures ${ }^{23}$, forensics ${ }^{27,} 28$, pharmaceuticals and beverages ${ }^{27}$ and breakfast cereals ${ }^{29}$. Direct photochemically induced UV-detection has also been applied for simultaneous 
analysis of underivatized cellodextrin oligomers up to degree of polymerization 7 (DP7) with similar LOD $(\sim 40 \text { to } 50 \mu \mathrm{M})^{30}$. So far, the UV-photochemical approach has not been yet reported for the analysis of longer polysaccharides.

Recently, Saetear et al. reported Taylor Dispersion Analysis (TDA) of non-UV absorbing polysaccharides using backscattering interferometry detection (BSI), which is a universal detector as defined by IUPAC (i.e. a detector that responds to every component except the mobile phase) based on refractive index (RI) ${ }^{31}$. TDA is a straightforward, simple and absolute method (no calibration), which only requires the knowledge of the solvent viscosity and capillary radius, allowing the determination of diffusion coefficient (or hydrodynamic radius $R_{h}$ ), relying on the dispersion of a sample plug under laminar Poiseuille-like flow. TDA presents many advantages: no stationary phase (no undesirable interactions), small injected volumes (nL), no sample filtration, insensitivity to dust, and access to the mass- $R_{h}$ distribution. If BSI allows the detection of non-UV absorbing (macro)molecules, it requires specific equipments with an optical breadboard, which are not provided with commercial CE instrumentations. Moreover, TDA-BSI sensitivity of detection is relatively low (LOD 50-80 mg/L in frontal mode ${ }^{31}$ ). To widen the applications of TDA to non-UV absorbing polysaccharides (including starches), we investigated UV-POD detection mode for TDA and we compared the results to those obtained using BSI. Furthermore, TDA results were also compared to dynamic light scattering (DLS) measurements performed in the same conditions as for the TDA experiments. Advantages and disadvantages of BSI vs UV-POD, on the one hand, and TDA vs DLS, on the other hand, are discussed.

\section{Experimental}

\subsection{Materials and reagents}


Glucan compounds used in this work were mono-, di-, tetra- oligosaccharides and $\alpha$-D-glucan polysaccharides. D-(+)-glucose monohydrate $\left(\mathrm{C}_{6} \mathrm{H}_{12} \mathrm{O}_{6} \cdot \mathrm{H}_{2} \mathrm{O}\right)$ was purchased from Alfa Aesar GmbH \& Co KG, Germany (product no. A11090). D-(+)maltose monohydrate $\left(\mathrm{C}_{12} \mathrm{H}_{22} \mathrm{O}_{11} \cdot \mathrm{H}_{2} \mathrm{O}\right)$ was purchased from Sigma Aldrich, Japan (product no. 63418) and maltotetraose, Dp4 $\left(\mathrm{C}_{24} \mathrm{H}_{42} \mathrm{O}_{11}\right)$ was purchased from Supelco, USA (product no. 47877). All the polysaccharides studied in this work are presented in Table 1.

Table 1. Presentation of the polysaccharides studied in this work.

\section{Polysaccharide General chemical structure Polymer characteristics}

$\begin{array}{ll}\text { Dextran } & \begin{array}{l}\text { Branched polysaccharide (branching } \\ \text { degree } 5 \%)\end{array} \\ \text { High dispersity }(>>1)^{41,50}\end{array}$

Pullulan

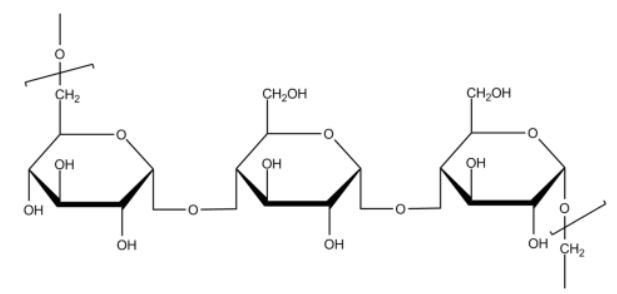

Glycogen

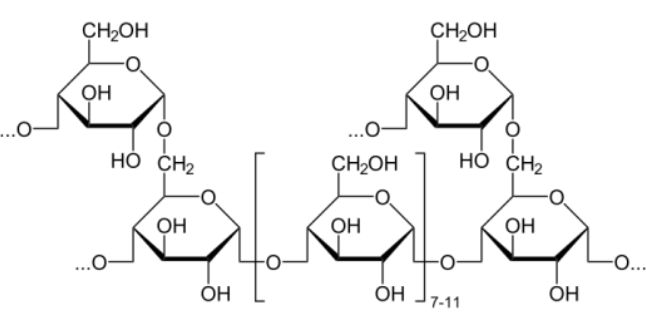

Linear polysaccharide

Low dispersity $(\sim 1)^{41,50}$
Branched polysaccharide with densely packed branches (branching degree $8-10 \%$ ) High dispersity (>>1) 
Starch

Amylose

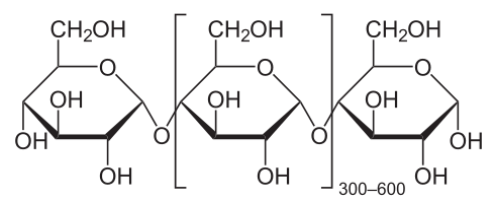

Amylopectin

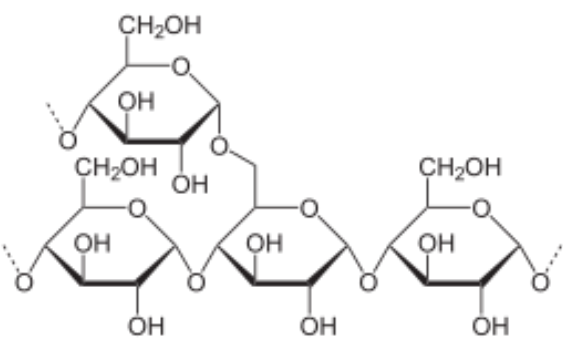

Amylose: Quasi-linear

polysaccharide (25\% in normal

maize starch) ${ }^{35}$

Amylopectin (75\% in normal maize starch): Branched polysaccharide with arborescent branching structure (branching degree 3.1-4.9\%) ${ }^{13} \mathrm{High}$ dispersity (>>1) 
Dextran T500 and dextran T2000 were supplied by Amersham Pharmacia Biotech (Uppsala, Sweden). Pullulan P400 and pullulan P800 were from Showa Denko K.K. (Tokyo, Japan). Glycogen from oyster-Type II was from Sigma Chemical Company (St Louis, MO). Phytoglycogen was extracted, as previously described by RollandSabaté et $\mathrm{al}^{32}$ from maize Sugary-1 provided by INRA (Plant Breeding Department, Clermont-Ferrand, France). Normal maize starch (containing 25\% amylose) was from Roquette Frères (Lestrem, France) and amylose-free potato starch (containing 0\% amylose) was from Lyckeby Stärkelsen Food \& Fiber AB (Kristianstad, Netherlands). Cassava amylopectin (containing 0\% amylose) was extracted from cassava starch by thymol complexation.

$\mathrm{NaOH}$ and $\mathrm{KOH}$ were from Merck (Germany). Ultra-pure water $(18 \mathrm{M} \Omega \mathrm{cm}$ ) purified on a Milli-Q system from Millipore (Molsheim, France) was used to prepare all solutions.

\subsection{Samples and eluents}

All polysaccharides were received in powder form. Sample solutions were prepared by dissolving the appropriate amount in the appropriate eluents. For TDAUV-POD experiments, $130 \mathrm{mM} \mathrm{NaOH}$ was used as eluent (to ensure photooxidation under UV radiations at the detection point) for all polysaccharides that are soluble in water (i.e., dextrans, pullulans and glycogens) ${ }^{32,50,53}$. Amylopectin and starch have a poor solubility in water and in $130 \mathrm{mM} \mathrm{NaOH}$ at concentrations higher than $1 \mathrm{~g} . \mathrm{L}^{-1}$, that is why they were dissolved in $1 \mathrm{M} \mathrm{KOH}$ for $72 \mathrm{~h}$ at $4{ }^{\circ} \mathrm{C}$ with mild stirring, and then analyzed in the same eluent by TDA-UV-POD. This solubilization procedure is known to be efficient for starch polysaccharides ${ }^{32}$. For TDA-BSI experiments, nonstarch polysaccharides (including dextrans, pullulans and glycogens) were dissolved 
in ultra-pure water since the presence of $\mathrm{NaOH}$ was not required for this mode of detection. DLS was performed using the same eluent as for TDA (see Table 2).

Table 2. TDA conditions for analysis of polysaccharides using UV-POD and BSI.

\begin{tabular}{|c|c|c|}
\hline Condition & TDA-UV-POD & TDA-BSI \\
\hline CE apparatus and set detection & Beckman Coulter, & Beckman Coulter, \\
\hline wavelength $(\mathrm{nm})$ & 214 and $266 \mathrm{~nm}^{\mathrm{a}}$ & 214 \\
\hline Capillary length (cm) & 40 & 160 \\
\hline Inner diameter (i.d., $\mu \mathrm{m}$ ) & 50 & 100 \\
\hline Outer diameter (o.d., $\mu \mathrm{m}$ ) & 360 & 200 \\
\hline \multirow[t]{2}{*}{ Detection window from the inlet $(\mathrm{cm})$} & 30 & 80.5 (BSI) \\
\hline & & 150 (UV) \\
\hline \multirow[t]{4}{*}{ Eluent } & $130 \mathrm{mM} \mathrm{NaOH}^{\mathrm{b}}$ & Water \\
\hline & $\left(\eta=0.998 \times 10^{-3} \mathrm{~Pa} \cdot \mathrm{s}\right)$ & $\left(\eta=0.890 \times 10^{-3} \mathrm{~Pa} \cdot \mathrm{s}\right)$ \\
\hline & or $1 \mathrm{M} \mathrm{KOH}^{\mathrm{c}}$ & \\
\hline & $\left(\eta=1.048 \times 10^{-3} \mathrm{~Pa} \cdot \mathrm{s}\right)$ & \\
\hline \multirow[t]{2}{*}{ Sample } & Polysaccharides $^{\mathrm{b}}$ & Polysaccharides \\
\hline & Amylopectin and starch ${ }^{c}$ & \\
\hline \multirow[t]{2}{*}{ Hydrodynamic injection } & $0.2 \mathrm{psi}$ for $8 \mathrm{~s}(4.07 \mathrm{~nL})$ & $0.3 \mathrm{psi}$ for $20 \mathrm{~s}(71.3 \mathrm{~nL})$ \\
\hline & $\left(V_{\mathrm{i}} / V_{\mathrm{d}}=0.7 \%\right)$ & $\left(V_{\mathrm{i}} / V_{\mathrm{d}}=1.1 \%\right)$ \\
\hline Mobilization pressure (psi) & 0.1 & 0.4 \\
\hline Linear velocity $\left(\mathrm{mm} \mathrm{s}^{-1}\right)$ & 0.19 & 0.6 \\
\hline Dilution Factor (for $R_{h}=10$ and 100 & $3.5-11$ & $13-42$ \\
\hline
\end{tabular}

${ }^{\text {aT }}$ wo wavelengths were compared in UV-POD to detect the products of photooxidation.

${ }^{\mathrm{b}}$ TDA-UV-POD condition for glycogens, pullulans and dextrans

${ }^{\mathrm{C}}$ TDA-UV-POD condition for amylopectin and starch

\subsection{Taylor Dispersion Analysis}

TDA was performed using a P/ACE ${ }^{T M} M D Q$ system (Beckman, USA). Bare fused-silica capillaries were supplied from Polymicro technologies, USA. New capillaries were conditioned with the following flushes: $1 \mathrm{M} \mathrm{NaOH}$ for $60 \mathrm{~min}$; water 
for $60 \mathrm{~min}$ and eluent for $60 \mathrm{~min}$. TDA experiments were carried out at $25^{\circ} \mathrm{C}$. All samples were prepared in the eluent. Instrumental setup for BSI interface with the CE-UV equipment has been described in details elsewhere ${ }^{31}$. Experimental conditions of TDA for two detection systems (UV-POD and BSI) are summarized in Table 2.

TDA-UV-POD allows recording the taylorgram directly from the UV detector, whereas TDA-BSI allows recording the taylorgrams in sequence by BSI and UV detectors (for more detail on the setup, see ref. 31). For UV detection, the absorbance detector was used and operated by Beckman Coulter's 32 Karat $^{\mathrm{TM}}$ Software 8.0. For BSI detection, data was recorded and stored on a computer via USB cable of the CCD array camera with an in-house software written using LabVIEW 2015 (National Instruments, USA). The phase (signal from BSI) of the recorded fringe pattern was extracted by using a Fourier-algorithm ${ }^{33,34}$. In our BSI configuration, the CCD camera orientation was upside-down. In other words, we obtained negative going phase values for increasing RI signals. Therefore, to meet with convention (increasing $\mathrm{RI}$ gives an increasing signal (phase value)), the absolute value (raw signal multiplied by -1 ) of the phase shift were recorded. All data obtained from BSI and UV were exported to Microsoft Excel for subsequent data processing using Microcal Origin 6.0. The peak variance was determined by the integration method described elsewhere ${ }^{35}$ to obtain the weight-average $R_{\mathrm{h}}$. Deconvolution of the signal by Constrained Regularized Linear Inversion (CRLI) ${ }^{36}$ were also applied to obtain the size distribution of the species in the sample. All samples were analyzed at least 2 times and the average $D$ (or $R_{\mathrm{h}}$ ) values, as well as the $R_{\mathrm{h}}$ distribution, were reported in Table 3. 
Table 3. Comparison of quantitative data on hydrodynamic radius $\left(R_{\mathrm{h}}\right)$ of oligo $\alpha$-D-glucans and $\alpha$-D-glucan polysaccharides obtained from TDABSI, TDA-UV-POD and DLS.

\begin{tabular}{|c|c|c|c|c|c|c|c|c|c|c|}
\hline \multirow{3}{*}{ Sample } & \multirow{3}{*}{$\begin{array}{c}\text { Molar } \\
\text { mass } \\
\left(\mathrm{g} \mathrm{mol}^{-1}\right)\end{array}$} & \multirow{3}{*}{$\begin{array}{l}\text { Dispersity } \\
M_{w} / M_{n}\end{array}$} & \multicolumn{8}{|c|}{ Hydrodynamic radius $\left(R_{\mathrm{h}}, \mathrm{nm}\right)$} \\
\hline & & & \multicolumn{3}{|c|}{ Water as eluent } & \multicolumn{3}{|c|}{$130 \mathrm{mM} \mathrm{NaOH}$ as eluent } & \multicolumn{2}{|c|}{$1 \mathrm{M} \mathrm{KOH}$ as eluent } \\
\hline & & & $\begin{array}{l}\text { TDA-BSI } \\
(n=3)\end{array}$ & $\begin{array}{l}\text { DLS } \\
\text { online }\end{array}$ & $\begin{array}{l}\text { DLS } \\
\text { batch }^{\text {h }}\end{array}$ & $\begin{array}{l}\text { TDA UV-POD } \\
214 \mathrm{~nm}(n=3)\end{array}$ & $\begin{array}{l}\text { TDA UV-POD } \\
266 \mathrm{~nm}(n=3)\end{array}$ & $\begin{array}{l}\text { DLS batch } \\
(n=2)\end{array}$ & $\begin{array}{l}\text { TDA-UV-POD } \\
266 \mathrm{~nm}(n=3)\end{array}$ & $\begin{array}{l}\text { DLS batch } \\
(n=2)\end{array}$ \\
\hline Glucose, DP1 & $180^{\mathrm{a}}$ & 1 & $0.33^{\mathrm{e}}$ & NT & NT & NT & $0.49 \pm 0.04^{\dagger}$ & NT & NT & NT \\
\hline Maltose, DP2 & $342.31^{\mathrm{a}}$ & 1 & $0.46^{\mathrm{e}}$ & NT"- & NT'- & NT' & NT & NT" & NT & NTT \\
\hline Malitotetraose, DP4 & $666.58^{a-}$ & 1 & $0.61^{\mathrm{e}}$ & $\mathrm{NT}$ & $\mathrm{NT}$ & $\mathrm{NT}^{--}$ & NT & $\mathrm{NTT}$ & NT & $\mathrm{NT}$ \\
\hline Dextran T500 & $\begin{array}{c}4.64-4.866 \\
\times 10^{5 c, d}\end{array}$ & $1.27-1.69^{\mathrm{c}, \mathrm{d}}$ & $\begin{array}{l}12.5 \pm \\
0.5^{\dagger}\end{array}$ & $\begin{array}{l}18.5^{-} \\
21.1^{\mathrm{b}, \mathrm{c}}\end{array}$ & $\begin{array}{l}32.8 \text { (cum) } \\
13.1 \\
(51.8 \%, \\
\text { contin) }\end{array}$ & $19.8 \pm 0.3^{\top}$ & $\begin{array}{l}12.3 \pm 0.5^{\dagger} \\
11.8^{9}(100 \%)\end{array}$ & $\begin{array}{l}15.1 \text { (cum) } \\
14.9(71.1 \%, \\
\text { contin) }\end{array}$ & NT & NT' \\
\hline Dextran T2000 & $\begin{array}{c}2.96-3.27 \\
\times 10^{6 c, d}\end{array}$ & $2.41-3.49^{\mathrm{d}}$ & $\begin{array}{l}18.8 \pm \\
0.5^{\dagger}\end{array}$ & $\begin{array}{l}42.4^{c-} \\
48.2^{c, d}\end{array}$ & $\begin{array}{l}54.9 \pm 9.5 \\
\text { (cum) } \\
55.5 \pm 4.0 \\
(86.3 \%, \\
\text { contin) }\end{array}$ & $41.8 \pm 2.9$ & $\begin{array}{l}18.9 \mathrm{~s} \pm 0.5^{\dagger} \\
15.0^{9}(70 \%) \\
32.8^{9}(30 \%)\end{array}$ & $\begin{array}{l}39.3 \pm 1.3 \\
\text { (cum) } \\
49.8(98.9 \% \\
\text { contin) }\end{array}$ & NT & NT' \\
\hline Pullulan P400 & $4.04 \times 10^{5 \mathrm{a}}$ & $1.06^{\mathrm{a}}$ & $\begin{array}{l}16.1 \pm \\
0.8^{\mathrm{f}}\end{array}$ & $18.4^{c, d^{-}}$ & 21 & $29.8 \pm 1.1^{f}$ & $\begin{array}{l}16.0 \pm 0.4^{\dagger} \\
17.1^{g}(100 \%)\end{array}$ & 19.2 (cum) & NT & NT \\
\hline Pullulan P800 & $7.88 \times 10^{5 \mathrm{a}}$ & $1.06^{\mathrm{a}}$ & $\begin{array}{l}21.7 \pm \\
0.3^{4}\end{array}$ & $\begin{array}{l}25.3- \\
26.5^{c, d}\end{array}$ & $27 \pm 4.4$ & $38.5 \pm 1.8$ & $\begin{array}{l}20.3 \pm 0.6^{\top} \\
20.9^{9}(100 \%)\end{array}$ & 23.0 (cum) & NT & $\mathrm{NT}$ \\
\hline Oyster glycogen & $\begin{array}{c}7.41-6.09 \times \\
10^{6 c, d}\end{array}$ & $1.16-1.35^{\mathrm{c}, \mathrm{a}}$ & $\begin{array}{l}12.4 \pm \\
0.3^{\mathrm{f}}\end{array}$ & $\begin{array}{l}22.5- \\
22^{\mathrm{c}, \mathrm{d}}\end{array}$ & $23.2 \pm 1.1$ & $\begin{array}{l}19.0 \pm 0.7^{-} \\
2.0^{\dagger}\end{array}$ & $\begin{array}{l}12.5 \pm 0.3^{1} \\
12.2^{9}(100 \%)\end{array}$ & $\begin{array}{l}27.3 \pm 0.3 \\
\text { (cum) }\end{array}$ & $\overline{\mathrm{NT}}$ & NT \\
\hline $\begin{array}{l}\text { Maize } \\
\text { Phytoglycogen }\end{array}$ & $1.67 \times 10^{7-}$ & $1.24^{\mathrm{d}}$ & $\begin{array}{l}20.5 \pm \\
0.3^{f}\end{array}$ & $29.0^{c}$ & $39 \pm 2.0$ & $\begin{array}{l}28.2 \pm 1.1^{\top} \\
(n=5)\end{array}$ & $\begin{array}{l}20.5 \pm 0.5^{\dagger} \\
3.4^{\mathrm{g}}(1.7 \%) \\
22.3^{\mathrm{g}}(98.3 \%)\end{array}$ & $\begin{array}{l}29.6 \pm 1.0 \\
\text { (cum) }\end{array}$ & $\mathrm{NT}$ & NT' \\
\hline $\begin{array}{l}\text { Cassava } \\
\text { amylopectin }\end{array}$ & $1.37 \times 10^{86}$ & $1.44^{\mathrm{b}}$ & $\mathrm{NT}$ & $\mathrm{NT}^{-}$ & $\mathrm{NT}$ & NT & NT & $\mathrm{NT}$ & $\begin{array}{l}74.9^{\top} \\
5.8^{9}(3 \%) \\
22^{g}(19 \%) \\
92^{g}(78 \%)\end{array}$ & $124.4 \pm 3.7$ \\
\hline $\begin{array}{l}\text { Normal maize } \\
\text { starch (75\% } \\
\text { amylopectin, } 25 \% \\
\text { amylose) }\end{array}$ & $\begin{array}{l}1.98-2.50 \\
\times 10^{8, \mathrm{i}, \mathrm{j}}\end{array}$ & $2.1^{\top}$ & $\mathrm{NT}$ & NT" & $201^{\top}$ & $\mathrm{NT}$ & NT & $\mathrm{NT}$ & $\begin{array}{l}109^{\dagger} \\
14.5^{g}(23 \%) \\
119^{9}(77 \%)\end{array}$ & $273.0 \pm 37.8$ \\
\hline $\begin{array}{l}\text { Amylose-free } \\
\text { potato starch } \\
(100 \%\end{array}$ & $\begin{array}{c}1.05-1.09 \times \\
10^{8 b, c}\end{array}$ & $1.16^{\mathrm{b}}$ & $\mathrm{NT}$ & $\mathrm{NT}$ & $\mathrm{NT}$ & $\mathrm{NT}$ & NT & $\mathrm{NT}$ & $\begin{array}{l}132.5^{1} \\
7.1^{9}(2 \%) \\
144^{9}(98 \%)\end{array}$ & $212.9 \pm 23.7$ \\
\hline
\end{tabular}


a Indicated by manufacturer.

${ }^{\mathrm{b}}$ Ref ${ }^{13}$

${ }^{\mathrm{c}}$ Ref ${ }^{41}$.

${ }^{\mathrm{d}} \operatorname{Ref}^{50}$.

erom Gaussian fitting.

${ }^{f}$ By left-part integration of the taylorgram using eqs 1 and 2. \pm one SD $(n=3)$.

${ }^{9}$ Modes obtained by CRLI curve fitting ${ }^{36}$ (mass proportion of each population).

${ }^{\mathrm{h}}$ By DLS with cumulant (cum) or contin data treatment. The data were obtained after averaging of ten autocorrelation functions for each sample acquisition.

Data in parentheses represent the proportions of the corresponding population found in the sample. \pm one SD ( $n=2)$.

${ }^{\mathrm{i}}$ Ref ${ }^{52}$

${ }^{\mathrm{j}}$ Ref ${ }^{40}$

${ }^{\mathrm{k}}$ By DLS with cumulant data treatment followed by extrapolation using a dynamic Zimm plot (see methods section). \pm one SD ( $n=2$ ). The data were obtained after averaging of ten autocorrelation functions for each sample acquisition.

NT: not tested. 


\subsection{Dynamic light scattering (DLS) operated in batch mode.}

Experiments were made in the homodyne mode with full photon-counting detection, using two phototubes in the pseudo-crosscorrelation configuration. The incident radiation (in-vacuo wavelength $\lambda=532.5 \mathrm{~nm}$ ) was obtained from a vertically polarized frequency-doubled Nd-YAG laser diode. The experiments were performed using a commercial set up (Amtec Goniometer and Brookhaven BI-9000AT correlator). Measurements were performed at $25^{\circ} \mathrm{C}$, at five scattering angles in the range $30^{\circ}$ to $120^{\circ}$ for starches and amylopectin at $0.5 \mathrm{~g} \mathrm{~L}^{-1}$ in $1 \mathrm{M} \mathrm{KOH}$, and at $60^{\circ}$ and $90^{\circ}$ for the other polysaccharides in water, and in $130 \mathrm{mM} \mathrm{NaOH}$ : at $2 \mathrm{~g} \mathrm{~L}^{-1}$ for glycogens and pullulans, at $1 \mathrm{~g} \mathrm{~L}^{-1}$ for dextran T2000, and at $4 \mathrm{~g} \mathrm{~L}^{-1}$ for dextran T500. For each sample acquisition, ten autocorrelation functions (acquisition duration: one minute) were merged and subsequently submitted to data treatment.

The merged autocorrelation functions were processed using two different methods: (i) the cumulant analysis ${ }^{37}$ and (ii) the CONTIN inversion routine ${ }^{38,39}$, which yields the distribution of relaxation times from the measured autocorrelation functions.

The hydrodynamic radii values were directly calculated using the first-order relaxation rate $\Gamma$ obtained from a $2^{\text {nd }}$ order cumulant analysis, excepted for starches and amylopectin for which a dynamic Zimm plot was constructed to extrapolate the apparent diffusion coefficient $D_{\text {app }}=\Gamma / q^{2}$ to the zero- $q$ limit, at a given concentration. Here $q=4 \pi n / \lambda \sin (\theta / 2)$ is the magnitude of the scattering vector ${ }^{40}, n$ the solution refractive index and $\theta$ the scattering angle. The angular extrapolation for the dynamic Zimm plot was made using a second-order polynomial fit because of the important curvature observed at high $q$ values. Despite of the high $q R_{g}$-range (where $R_{g}$ is the $z$-average radius of gyration) used in this study (1.4 to 6.6 , calculated from the $R_{\mathrm{g}}$ values reported by Rolland-Sabaté et al., $\left.{ }^{13},{ }^{41}\right)$, it was possible to obtain 
hydrodynamic radii values for the starch samples by direct use of a dynamic Zimm plot thanks to the high quality of this diagram (Figure S1 in Supplementary Information).

\section{Results and discussion}

\subsection{Choice of the wavelength and detection response in UV-POD}

TDA-UV-POD was performed on a $50 \mu \mathrm{m} \times 40 \mathrm{~cm}$ fused silica capillary using $130 \mathrm{mM} \mathrm{NaOH}$ as mobile phase and in sample matrix (see Table 2 and experimental section 2.3 for more details). Very low mobilization pressure $(0.1 \mathrm{psi} \approx 7 \mathrm{mbar})$, corresponding to a linear velocity of $0.19 \mathrm{~mm} \mathrm{~s}^{-1}$, was used to maximize the response of the detector by increasing the amount of UV-absorbing species that are produced in front of the UV detection window, in agreement with what was previously observed for monosaccharides ${ }^{22}$. Figure 1 displays the UV taylorgrams obtained for pullulan P400 $\left(20 \mathrm{~g} \mathrm{~L}^{-1}\right)$ at $214 \mathrm{~nm}$ (black trace) and at $266 \mathrm{~nm}$ (red trace).

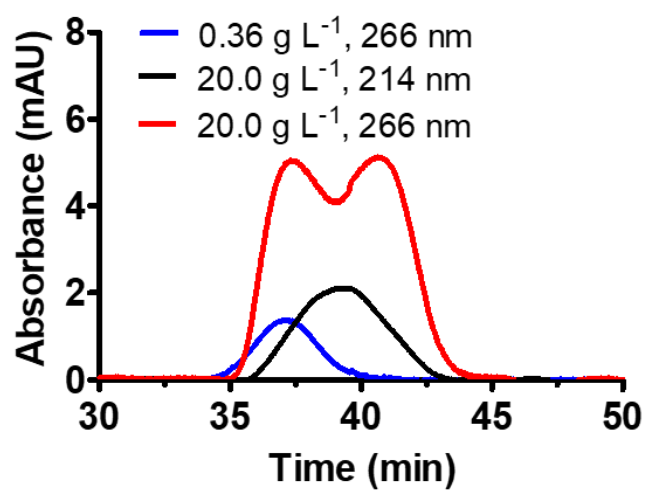

Figure 1. Taylorgrams of pullulan P400 obtained by TDA-UV-POD at $214 \mathrm{~nm}$ (black trace) and $266 \mathrm{~nm}$ (red and blue traces). The dip in the red curve was due to nonlinear response of the photooxidation products, which disappeared by reducing the concentration (blue line, preferred) or by changing the wavelength (black line). Experimental conditions: $50 \mu \mathrm{m} \times 40$ $\mathrm{cm}$ (30 $\mathrm{cm}$ to the detector) fused silica capillary. Eluent: $130 \mathrm{mM} \mathrm{NaOH}$. Injection: $0.5 \mathrm{psi}$, 4s. Mobilization pressure: 0.1 psi. Pullulan P400 sample: $20 \mathrm{~g} \mathrm{~L}^{-1}$ (black and red traces) and 
$0.36 \mathrm{~g} \mathrm{~L}^{-1}$ (blue trace) in $130 \mathrm{mM} \mathrm{NaOH}$. Other experimental conditions as described in Table 2.

Clearly, the UV response was much higher at $266 \mathrm{~nm}$ compared to $214 \mathrm{~nm}$, but the signal at $266 \mathrm{~nm}$ displayed a dip at the peak apex, which was not observed at 214 $\mathrm{nm}$. This peculiar behavior can be related to kinetics and nonlinear response effects due to this specific detection mode involving complex photochemical reactions with the formation of UV-absorbing intermediates (maximum of absorbance between 260 and $270 \mathrm{~nm}^{22-24}$ ). Decreasing the concentration of the injected sample to $0.36 \mathrm{~g} \mathrm{~L}^{-1}$ (blue trace) allowed to remove the dip seen at $266 \mathrm{~nm}$, while keeping a sufficient sensitivity to detect the polymer. At the same concentration, the signal was too weak to be detected at $214 \mathrm{~nm}$. Working at $266 \mathrm{~nm}$ is also preferable, since it allows for the injection of more diluted, and thus, less viscous samples. The linearity of the UV response was next investigated at both wavelengths for all analyzed solutes by injecting a large sample plug, using the same mobilizing linear velocity $\left(0.19 \mathrm{~mm} \mathrm{~s}^{-1}\right)$. Typical examples of recorded signals are provided in Figure S2. The corresponding calibration curves are displayed in Figure 2 for glucose, pullulan P800, dextran T2000 and amylose-free potato starch (all other samples are presented in Figure S3). 

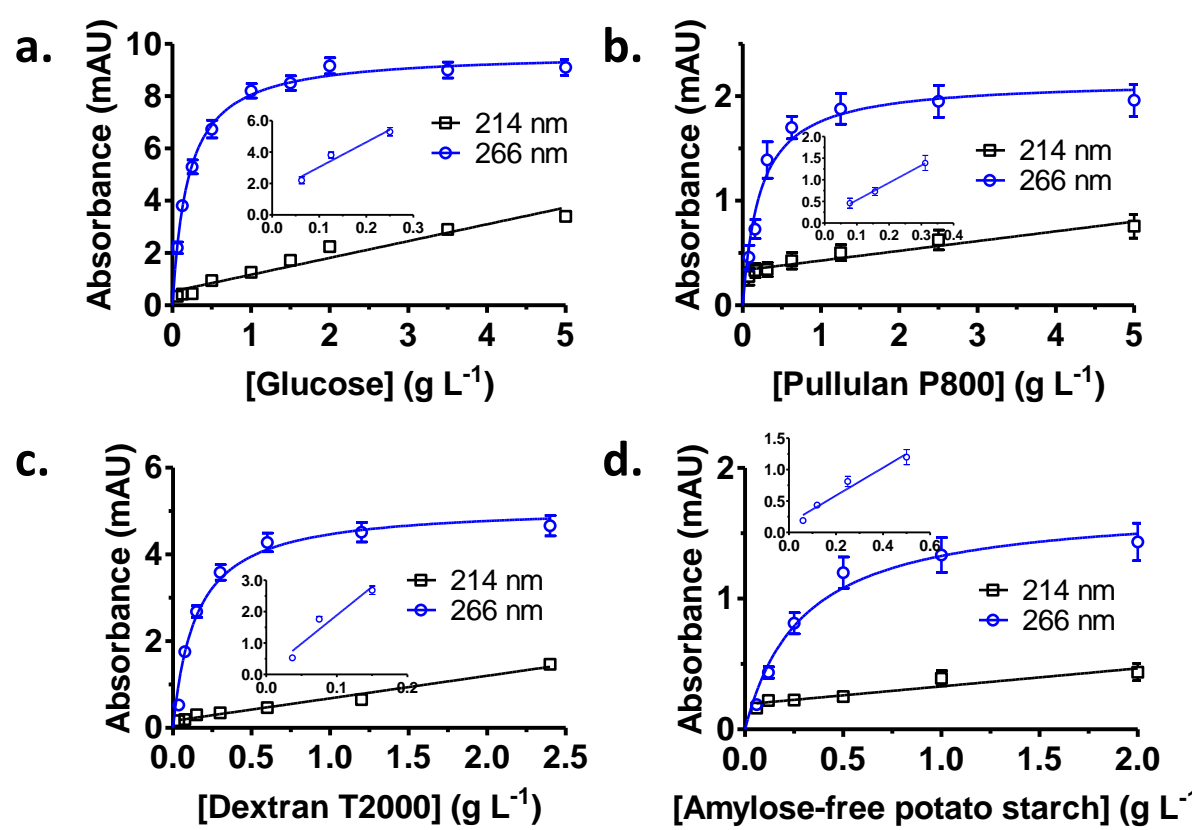

[Amylose-free potato starch] ( $\left.\mathrm{g} \mathrm{L}^{-1}\right)$

Figure 2. Signal response by POD for glucose, pullulan P800, dextran T2000 and amylosefree potato starch, obtained at 214 and $266 \mathrm{~nm}$ by large plug injections. Better sensitivity was obtained at $266 \mathrm{~nm}$ (blue trace) than at $214 \mathrm{~nm}$ (black trace), but the linear range was relatively short. Inserts show the linear responses at $266 \mathrm{~nm}$. Experimental conditions: 50 $\mu \mathrm{m} \times 40 \mathrm{~cm}$ (30 cm to the detector) fused silica capillary. Eluent: $130 \mathrm{mM} \mathrm{NaOH}$ (except for starch, $1 \mathrm{M} \mathrm{KOH}$ ). Injection: $1 \mathrm{psi}, 60 \mathrm{~s}$. Mobilization pressure: $0.1 \mathrm{psi}$ (linear velocity, 0.19 $\mathrm{mm} / \mathrm{s}$ ). Sample at the indicated concentration in the eluent. Other experimental conditions as described in Table 2.

On the investigated concentration range (typically, $0-5 \mathrm{~g} \mathrm{~L}^{-1}$ ), saturation of the detection signal was always observed at $266 \mathrm{~nm}$. However, the sensitivity of detection was much higher at $266 \mathrm{~nm}$ than at $214 \mathrm{~nm}$, for all the solutes. Moreover, the linear calibration curves observed at $214 \mathrm{~nm}$ are not always passing through zero (see e.g. Figures $2 \mathrm{~b}$ and $2 \mathrm{~d}$ ). It is therefore preferable to work at $266 \mathrm{~nm}$, but the injected concentration should be carefully chosen to remain in the (relatively short) linear response range. To set the injected concentration, it is important to estimate the dilution factor (DF) between injection and detection points due to the Taylor dispersion that are given by equations ${ }^{43}(1 \mathrm{a})$ and $(1 \mathrm{~b})$ : 


$$
\begin{aligned}
& \mathrm{DF}=\frac{\sqrt{2 \pi} Q \sigma_{t}}{V_{i n j}} \\
& \mathrm{DF}=\frac{\pi^{2} R_{c}^{3} l}{V_{i n j}} \sqrt{\frac{\eta R_{h}}{2 k_{B} T t_{0}}}
\end{aligned}
$$

where $Q$ is the flow rate, $\sigma_{t}$ is the temporal standard deviation of the elution profile due to Taylor dispersion at a detection point placed at a distance / from the injection point, $R_{c}$ is the capillary radius, $k_{b}$ is the Boltzmann constant, $T$ is the temperature (in $\mathrm{K}), V_{\text {inj }}$ is the injected volume and $t_{0}$ is the average elution time. Typical DF about 3.5 to 11 are obtained on the TDA-UV-POD set-up for solutes having a $R_{\mathrm{h}}$ of 10 and 100 $\mathrm{nm}$, respectively. It is therefore advisable to set the sample concentration at the value for which the UV response start to level off, so that the working concentration at the detection point remains in the linear range, taking into account the DF. Injected sample concentrations were chosen around $0.25-0.5 \mathrm{~g} \mathrm{~L}^{-1}$ for dextran, pullulan and starch; and were one order of magnitude higher $\left(\sim 5 \mathrm{~g} \mathrm{~L}^{-1}\right)$ for glycogen samples.

\subsection{Determination of the average hydrodynamic radius}

Following the results obtained in the previous section, TDA-UV-POD was performed on the polysaccharide samples tested in this work (see Table 1), by monitoring the response at $266 \mathrm{~nm}$, using injected concentrations between $0.25 \mathrm{~g} \mathrm{~L}^{-1}$ and $5 \mathrm{~g} \mathrm{~L}^{-1}$, depending on the calibration curve. As a matter of comparison, TDA-UVPOD was also performed at $214 \mathrm{~nm}$, using much higher injected concentrations (20 $\mathrm{g} \mathrm{L}^{-1}$ ). All TDA-UV-POD analyses were performed in $130 \mathrm{mM} \mathrm{NaOH}$ eluent (except for starch samples that are discussed later in the text). In a third independent series of analyses, TDA-BSI was implemented using pure water as eluent with polysaccharide concentration set at $20 \mathrm{~g} \mathrm{~L}^{-1}$. Due to different experimental 
requirements for TDA-UV-POD and TDA-BSI, the capillary dimensions, the eluent and the mobilization pressure were different (see Table 2 for the comparison of the experimental conditions). Example of taylorgrams obtained for these three series of experiments, are given in Figures 3a and 3c for dextran T500 and Figures $3 b$ and $3 d$ for oyster glycogen.

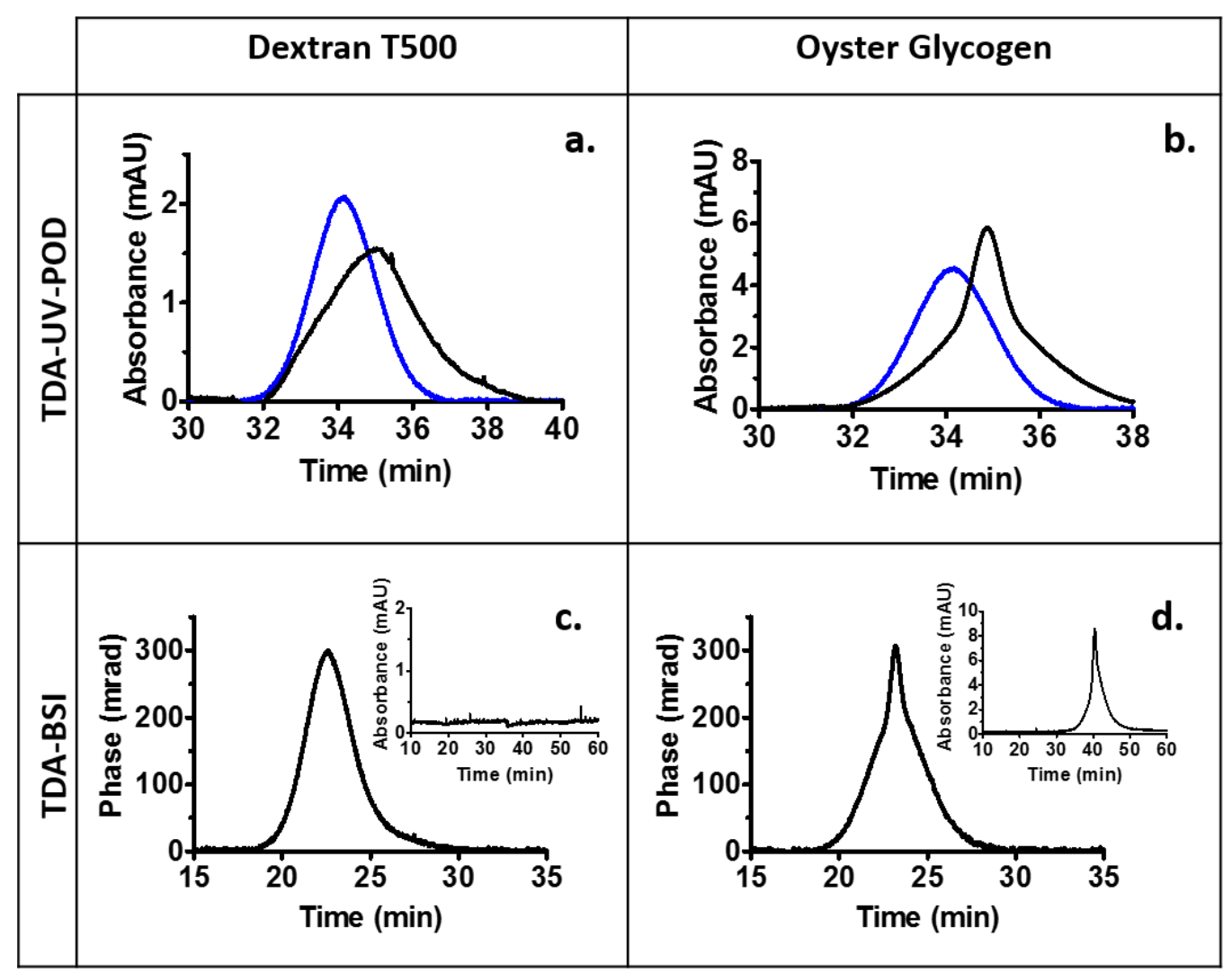

Figure 3. Taylorgrams obtained for dextran T500 ( $\mathrm{a}$ and $\mathrm{c}$ ) and oyster glycogen ( $\mathrm{b}$ and $\mathrm{d}$ ) by TDA-UV-POD ( $a$ and b) at $214 \mathrm{~nm}$ (black) and $266 \mathrm{~nm}$ (blue); and by TDA-BSI (c and d). Good agreement was obtained between UV-POD at $266 \mathrm{~nm}$ (blue trace) and BSI. Experimental conditions as described in Table 2. TDA-UV-POD and TDA-BSI were performed independently. Eluent: $130 \mathrm{mM} \mathrm{NaOH}$ for TDA-UV-POD and pure water for TDABSI. Mobilizing pressure: $0.1 \mathrm{psi}$ (TDA-UV-POD) or $0.4 \mathrm{psi}$ (TDA-BSI). Linear velocity: 0.19 $\mathrm{mm} \mathrm{s}^{-1}$ (TDA-UV-POD) or $0.6 \mathrm{~mm} \mathrm{~s}^{-1}$ (TDA-BSI). All sample solutions were prepared in the eluent. Dextran T500 injected concentrations: TDA-BSI $\left(20 \mathrm{~g} \mathrm{~L}^{-1}\right)$, TDA-UV-POD at $214 \mathrm{~nm}$ $\left(20 \mathrm{~g} \mathrm{~L}^{-1}\right)$, TDA-UV-POD at $266 \mathrm{~nm}\left(0.25 \mathrm{~g} \mathrm{~L}^{-1}\right)$. Oyster glycogen injected concentrations:

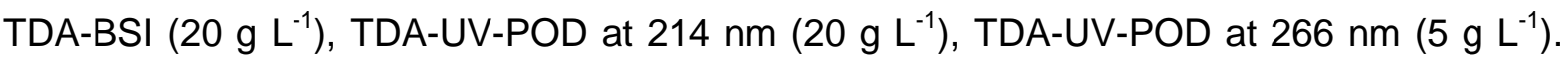
Inserts in $\mathrm{C}$ and $\mathrm{d}$ display the taylorgrams obtained by (normal) UV detection at $214 \mathrm{~nm}$ with pure water as eluent as for the TDA-BSI setup. 
Taylorgrams for the other polysaccharide samples (except starch samples) are displayed in Figure S4 in supplementary data. If TDA-BSI was able to detect all the polysaccharide samples, high injected concentrations were required to get sufficient signal. This was mainly due to higher DF on the $100 \mu \mathrm{m}$ i.d. capillary used with BSI detection, leading to DF of 13 and 42 for solutes having a $R_{\mathrm{h}}$ of 10 and $100 \mathrm{~nm}$, respectively. As expected, for most of the polysaccharide samples, the UV trace obtained in water at $214 \mathrm{~nm}$ during the TDA-BSI experiments did not give any response (see e.g. insert in Figure 3c), which rationalizes the use of TDA-BSI or TDA-UV-POD approaches. Only glycogen samples (oyster glycogen and phytoglycogen shown in insets of Figures $3 d$ and 3S-h, respectively) provide detectable UV traces in pure water. This can be explained by the well-known presence of proteins ${ }^{36}$ in these samples that are extracted either from oyster or plants, and that are not pure ( $\geq 75 \%$ purity).

UV-POD and BSI traces were analyzed to get the average $R_{h}$ by peak integration of the left (rising) part of the elution profile using the following equations:

$$
R_{h}=\frac{4 \sigma_{t}^{2} k_{B} T}{\pi \eta R_{c}^{2} t_{0}}
$$

The temporal variance of the elution profile was calculated using eq. (2): $:^{35,42}$

$$
\sigma_{t}^{2}=\frac{\int h(t)\left(t-t_{0}\right)^{2} d t}{\int h(t) d t}=\frac{\sum_{i=n}^{m} h_{i}\left(t_{i}-t_{0}\right)^{2}\left(t_{i+1}-t_{i}\right)}{\sum_{i=n}^{m} h_{i}\left(t_{i+1}-t_{i}\right)}
$$

where $h(t)$ is the detector response, $t_{i}$ is elution time for a given point $i$ of the taylorgram, and $n$ and $m$ are the starting and ending points that are considered for the integration of the taylorgram. The integration of signal is performed on the left part of the signal ${ }^{35}\left(t-t_{0} \leq 0\right)$ in order to avoid any bias on the $R_{h}$ determination due to possible adsorption of the solutes onto the capillary wall. For all measurements, 
the conditions of validity of TDA were fulfilled, with the numerical values of the dimensionless residence time $\tau \geq 1.25\left(\tau=D t_{0} / R_{c}^{2}\right)$ and the Péclet number $P_{e} \geq 40$ $\left(P_{e}=R_{c} u / D\right)^{43} . P_{e} \geq 40$ ensures that the dispersion due to axial diffusion is negligible compared to convection (Taylor dispersion). Quantitative data on average $R_{\mathrm{h}}$ values obtained by TDA and DLS in the same conditions are given in Table 3 for all samples ( $n=3$ repetitions). The average values obtained by TDA-BSI in water were very close to those obtained independently by TDA-UV-POD $(266 \mathrm{~nm})$ in $130 \mathrm{mM}$ $\mathrm{NaOH}$, for the 6 non-starch polysaccharides (dextrans, pullulans and glycogens), with typical $R_{h}$ values between 10 and $20 \mathrm{~nm}$. The average relative differences between the two detection modes was about $2 \%$. The repeatability $(n=3)$ was also very good for both detection modes, with average RSD below 3\%. These data demonstrate the robustness of TDA, whatever the detection mode. UV-POD (266 $\mathrm{nm}$ ) should however be preferred since the injected concentration is lower (less viscous injected samples), and the signal to noise ratio is higher (LOD significantly lower). LOD obtained for TDA-UV-POD $(266 \mathrm{~nm})$ are in the order of $40 \mathrm{mg} \mathrm{L}^{-1}$ for pullulans and dextrans (this work) versus $50-60 \mathrm{mg} \mathrm{L}^{-1}$ in TDA-BSI ${ }^{31}$. The polymer size obtained by TDA will be compared to that retrieved from DLS when discussing the full size distribution (see Section 3.3).

Numerical values obtained for the average $R_{h}$ from TDA-UV-POD $(214 \mathrm{~nm})$ experiments performed in $130 \mathrm{mM} \mathrm{NaOH}$ at high injected concentrations (about $20 \mathrm{~g}$ $\mathrm{L}^{-1}$ ), were always higher (see Table 3 ) than those previously reported for TDA-BSI or TDA-UV-POD (266 nm). This discrepancy cannot be explained by the high injected concentration since TDA-BSI was performed at the same concentration and provided accurate results. The reason is probably due to the poor linearity discussed in section 3.1, with calibration curves that do not pass through the origin. 
As for the TDA experiments on starch samples, instead of $130 \mathrm{mM} \mathrm{NaOH}, 1 \mathrm{M}$ $\mathrm{KOH}$ was used to dissolve the sample $\left(72 \mathrm{~h}\right.$ at $4{ }^{\circ} \mathrm{C}$ with mild stirring, see experimental section) and as mobile phase in the TDA experiments. In fact, the solubility of starches is a crucial and complicated issue ${ }^{44}$. The use of $1 \mathrm{M} \mathrm{KOH}$ is a good way to obtain full solubility, but low temperature $\left(4^{\circ} \mathrm{C}\right)$ conditions are important to avoid any cleavage of the polymer chain by $\beta$-elimination phenomenon at high $\mathrm{pH}$. Since $\mathrm{KOH}$ was required for the solubilization, it was readily suited for UV-POD detection at $266 \mathrm{~nm}$ with injected concentration set at $0.45 \mathrm{~g} \mathrm{~L}^{-1}$. Taylorgrams are displayed in Figure 4.
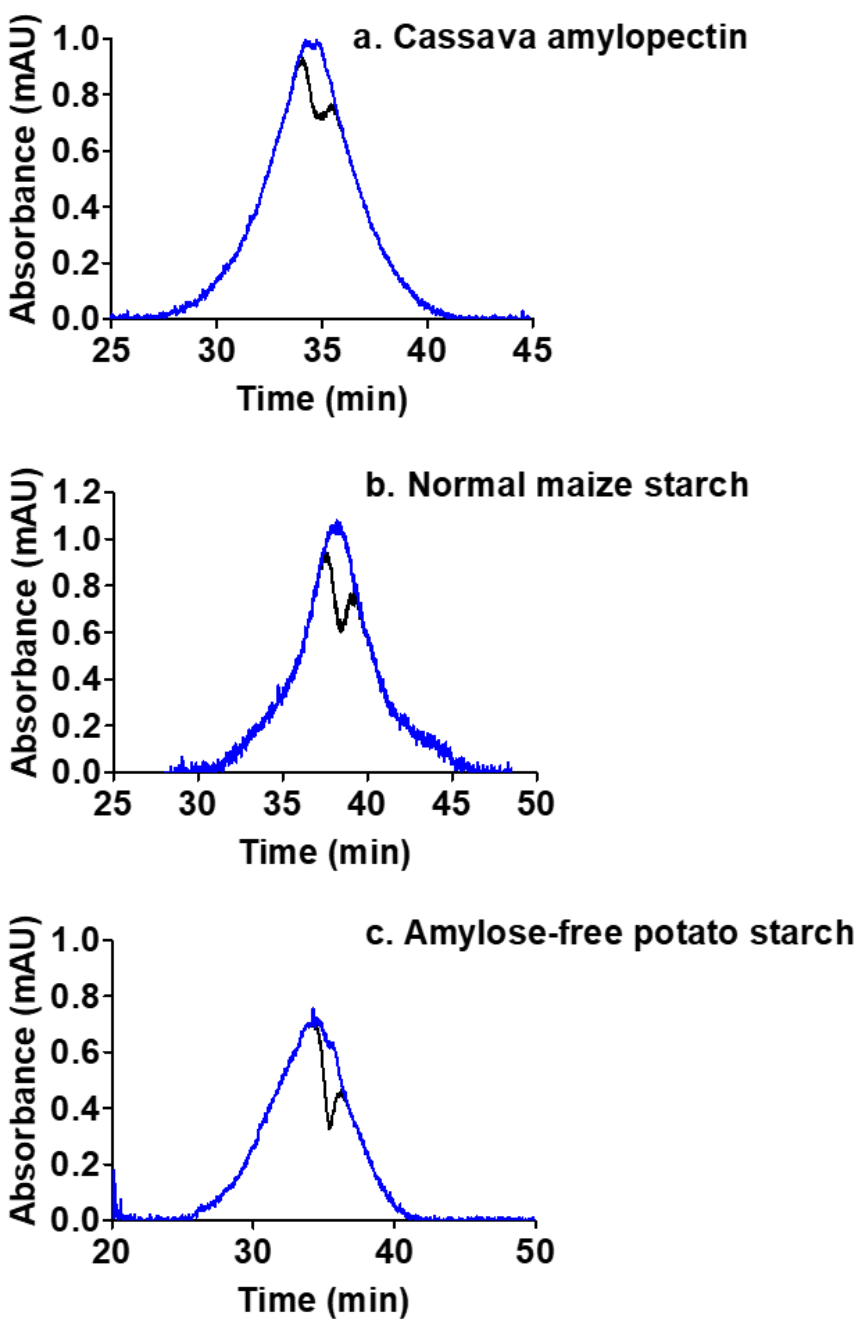

Figure 4. Taylorgrams of (a) Cassava amylopectin, (b) Normal maize starch (75\% amylopectin, 25\% amylose) and (c) amylose free potato starch (100\% amylopectin) obtained 
by TDA-UV-POD at $266 \mathrm{~nm}$. TDA traces (black) were corrected from buffer mismatch (blue). Experimental conditions: $50 \mu \mathrm{m} \times 40 \mathrm{~cm}$ (30 cm to the detector) fused silica capillary. Eluent: $1 \mathrm{M} \mathrm{KOH}$. Injection: $0.5 \mathrm{psi}, 4 \mathrm{~s}$. Mobilization pressure: $0.1 \mathrm{psi}$ (linear velocity: $0.19 \mathrm{~mm} \mathrm{~s}^{-1}$ ). All solutions were injected at $0.45 \mathrm{~g} \mathrm{~L}^{-1}$ in $1 \mathrm{M} \mathrm{KOH}$. Other experimental conditions as described in Table 2.

Despite a relatively low sensitivity of detection (maximum absorbance about $1 \mathrm{mAU}$; LOD about $85 \mathrm{mg} \mathrm{L}^{-1}$ ), the taylorgrams are exploitable with a good symmetry of the signal. A slight buffer mismatch ${ }^{45}$ appearing as a small negative absorbance close to the peak apex was corrected before the peak integration. Figure 4 shows both the traces before (black traces) and after (blue traces) the correction of the buffer mismatch. The average $R_{h}$ values obtained from TDA-UV-POD (266 nm) are comprised between $75 \mathrm{~nm}$ for cassava amylopectin and $133 \mathrm{~nm}$ for amylose-free potato starch (100\% amylopectin) (Table 3 ). The experimental TDA conditions should be carefully chosen to allow for the correct determination of the quite high $R_{\mathrm{h}}$ values $^{46}$ typically found for starch samples. On $50 \mu \mathrm{m}$ i.d. capillary, the maximum limit in size relative to the occurrence of hydrodynamic chromatography, for a maximal relative error on $D$ of $3 \%$, is about $R_{\mathrm{h}} \sim 130 \mathrm{~nm}$. In the case of potato amylopectin, the relative error $\varepsilon$ on $D$ (given by $\left.\varepsilon=\frac{R_{h}}{0.17 \times R_{c}}\right)^{46}$ is evaluated to be only $3.1 \%$. If we accept a maximal error of $5 \%$, this limit in size is increased up to $R_{\mathrm{h}}$ $210 \mathrm{~nm}$ on a $50 \mu \mathrm{m}$ i.d. capillary; which seems attractive for the analysis of starch samples in general. Regarding the dimensionless residence time $\tau$, it was calculated for the amylose-free potato starch as 5.3 (and higher values for the two other starch samples), ensuring the absence of any peak deformation toward the lower elution times due to the convective hydrodynamic regime $(\tau>1.25 \text { condition })^{46}$. 
Regarding the comparison between TDA and DLS in batch mode, the average $R_{h}$ obtained by TDA was always lower than that obtained by DLS for all the samples. This is well known and well understood ${ }^{42,47}$ since for mass sensitive detector such as RI-based detector (BSI) or UV-POD, TDA leads to the weightaverage $R_{\mathrm{h}}$ value $\left(R_{h, T D A}\right)$ while DLS provides harmonic z-average $R_{\mathrm{h}}$ values $\left(R_{h, D L S}\right)$ :

$$
\begin{aligned}
& R_{h, T D A}=\frac{\sum_{i} N_{i} M_{i} R_{h, i}}{\sum_{i} N_{i} M_{i}} \\
& R_{h, D L S}=\frac{\sum_{i} N_{i} M_{i}^{2}}{\sum_{i} \frac{N_{i} M_{i}^{2}}{R_{h, i}}}
\end{aligned}
$$

where $N_{i}$ is the number of moles species having a hydrodynamic $R_{h, i}$ and a molar mass $M_{i}$. The harmonic $z$-average value weights more the largest analytes/polymers than the weight-average value. Accordingly, the wider the size distribution, the higher the discrepancy between the TDA and DLS values of $R_{h}$. Sometimes, the $R_{h, D L S} /$ $R_{h, T D A}$ ratio (noted PDI hereafter) is given as an estimator of the size dispersity, as recently reported for the sizing of polydisperse microemulsions ${ }^{48,49}$. For instance, the PDI was much higher for dextran T2000 (PDI=2.16) than for pullulans (PDI between 1.1 and 1.2) which is in good agreement with the known lower dispersity in molar mass and size for these pullulans as compared to dextrans (Table 3 and ref. ${ }^{41,}{ }^{50}$ ). Moreover, glycogens exhibit also a high dispersity in molar mass and in size with PDI between 1.4 (phytoglycogen) and 2.1 (oyster glycogen). As for starch samples, PDI are even higher (between 1.6 and 2.7), due to the great heterogeneity of the samples. The higher value of PDI (2.7) obtained for normal maize starch was expected, as this sample, in contrast to the two other starches that contain only amylopectin, is constituted by a mixture of two macromolecules: amylose (25\%) and 
amylopectin (75\%), leading to a very high molar mass dispersity but also structural dispersity (linear vs branched polymer).

\subsection{Determination of the hydrodynamic radius distribution by deconvolution of the taylorgrams}

To obtain more information about the $R_{h}$ distribution, deconvolutions of the taylorgrams by Constrained Regularized Linear Inversion (CRLI) ${ }^{36}$ were also applied to obtain the entire size distribution of the polysaccharides. These distributions are presented in Figure 5 for all the samples (except pullulans which have a low dispersity). $R_{h}$ distributions of dextrans and glycogens are displayed in Figure 5a, while distributions of starch samples are presented in Figure 5b. Clearly, starch samples present bimodal (even trimodal for cassava amylopectin) distributions with a major mode around $100 \mathrm{~nm}$ and one or two other modes around 6 and $20 \mathrm{~nm}$. Among the non-starch polysaccharides, dextran T2000 appeared as the most polydispersed polysaccharide with two modes at 10-20 nm and 30-40 nm.
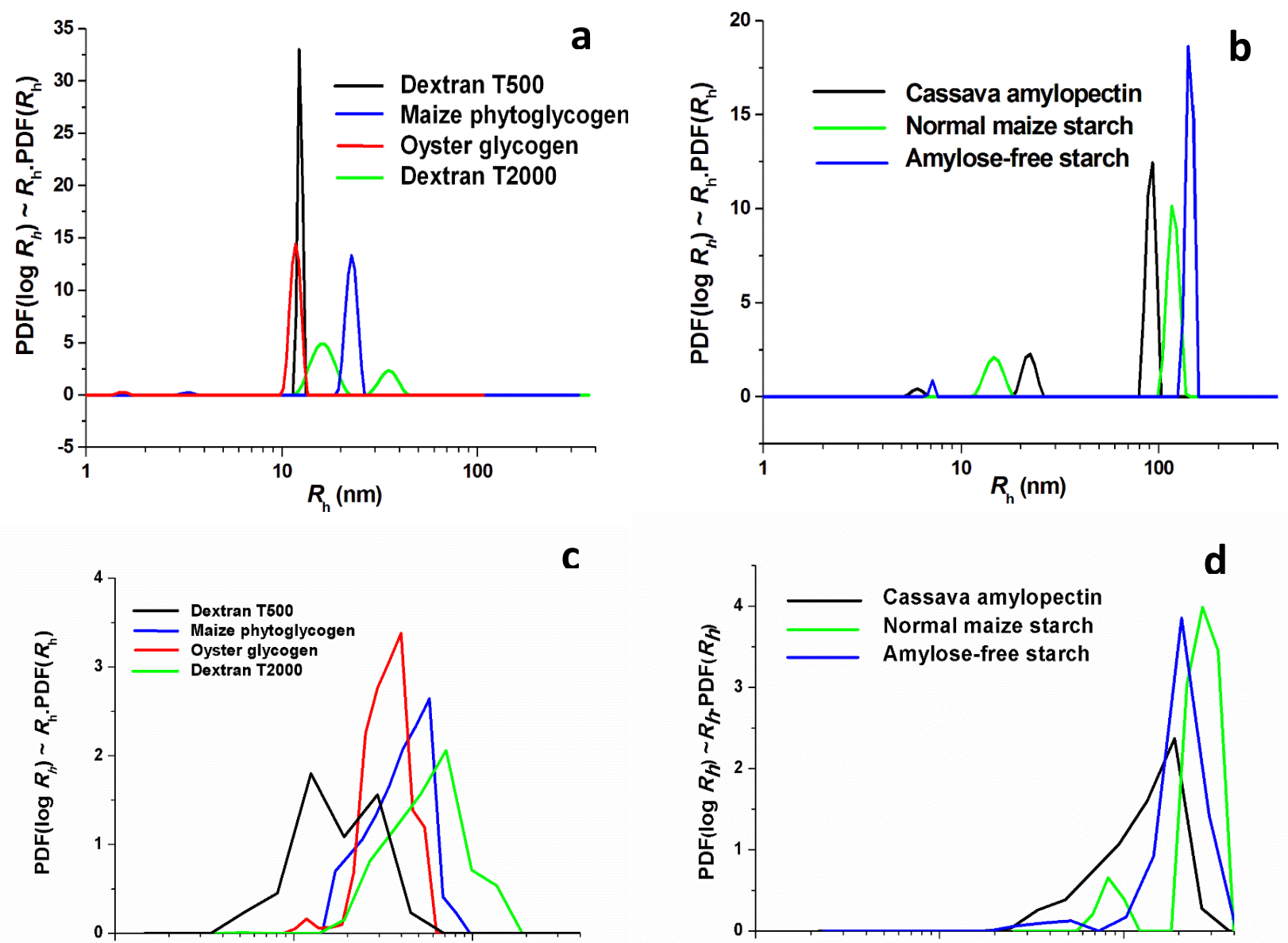

C

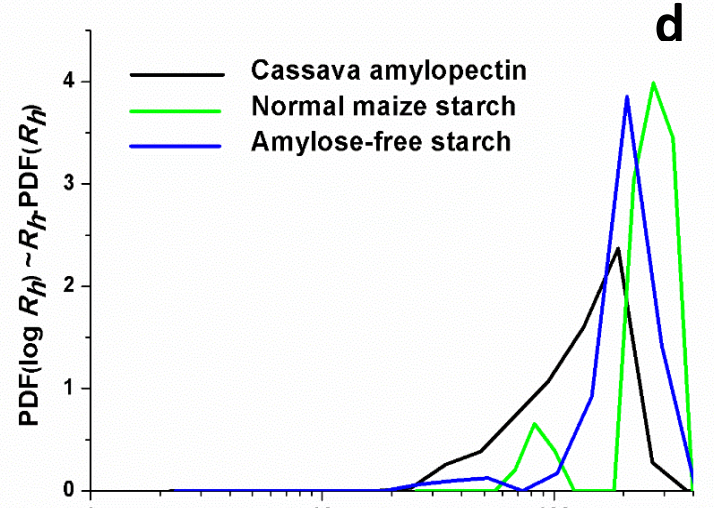


Figure 5. Hydrodynamic radius $\left(R_{h}\right)$ distributions obtained by CRLI with TDA-UV-POD at $266 \mathrm{~nm}(\mathrm{a}, \mathrm{b})$ and by DLS operated in batch mode (c, d) for dextrans and glycogens (a, c) and starches (b, d). Broader distributions shifted toward larger sizes were obtained by DLS compared to TDA. Experimental conditions as in Figures 3 and 4. DLS distributions represented here were obtained by a CONTIN analysis of data measured at $60^{\circ}$ for T500 and at $90^{\circ}$ for the other polysaccharides.

$R_{h}$ distributions obtained by DLS in batch mode are presented in Figures $5 \mathrm{c}$ and $5 \mathrm{~d}$. While it is instructive to compare the TDA and DLS data, the specificities of each method should be kept in mind. TDA provides a mass-weighted distribution of the hydrodynamic radius. The interpretation of the DLS signal is less straightforward. The PDF obtained through the CONTIN analysis yields the distribution of the hydrodynamic radii weighted by the scattering intensity associated to each size. For small objects, such that $R_{\mathrm{h}} q<1$, the scattered intensity is proportional to the squared mass of the object, regardless of its structure ${ }^{51}$. For the data shown in Figures $5 \mathrm{c}$ and $5 \mathrm{~d}$, this regime corresponds to $R_{\mathrm{h}} \leq 40 \mathrm{~nm}$. In the opposite limit $R_{\mathrm{h}} \geq$ $40 \mathrm{~nm}$, the scattered intensity depends in a non-trivial way both on the (squared) mass of the object and on its size and structure. Most of the data of Figure 5 encompass both regimes. It is therefore impossible to convert quantitatively the intensity-weighted PDF of $R_{\mathrm{h}}$ obtained by DLS to a mass-weighted, or even a squared-mass-weighted PDF to be directly compared to the TDA distribution. However, one can safely state that the DLS PDF weights more the larger objects as compared to the TDA data. 
For all the samples studied here we find that the $R_{h}$ distributions obtained by TDA are clearly narrower than those obtained by DLS. For Dextran T500 and the two glycogens (Figure 5a), TDA provides monomodal distributions in agreement with the refractive index traces obtained by HPSEC and/or Asymmetrical Flow Field-Flow Fractionation (AF4) in water ${ }^{50,53}$. Dextran T2000 sample exhibits a bimodal distribution in TDA which reflects its particularly high dispersity in size (PDI=2.16) and in molar mass $\left(M_{w} / M_{n}=2.41-3.49\right)^{41,50}$, observed in HPSEC as a broad mode with three maxima ${ }^{50}$ and as a broad mode with a shoulder toward larger sizes in AF4. The maxima of the size distributions exhibit a significant shift toward lower values for TDA as compared to DLS (as already observed for the average $R_{h}$ values). Concerning the differences between the distributions obtained by batch DLS and TDA, we note that aggregation may play a significant role, in addition to the fact that these methods intrinsically provide $R_{h}$ distributions weighted in a different way. Indeed, DLS data are obtained from samples that are more concentrated by a factor of 10 than for TDA (1-4 $\mathrm{g} \mathrm{L}^{-1}$ in DLS and 0.35/DF 0.1 $\mathrm{g} \mathrm{L}^{-1}$ in TDA-UV-POD), and hence more prone to aggregation.

Concerning the starch samples of Figures $5 b, 5 d$, the $R_{h}$ distributions obtained by both TDA and DLS exhibit polymodal distributions or broad distribution with a shoulder (Figure 5d) for cassava amylopectin. However, the shape of the distributions is quite different. Distributions obtained by DLS in batch mode are significantly broader and their maxima shifted to higher values of $R_{h}$, as compared to those issued from TDA (compare panels $b$ and $d$ of Figure 5). The greatest difference is seen for normal maize starch, whose PDF as retrieved by DLS contains the largest species of all starch-based samples. This is in contrast with the TDA data, for which amylose-free potato starch contains the largest objects. The 
discrepancy between TDA and batch DLS data could stem from the large dispersity in size, molar mass and structure of the starch molecules, in particular for normal maize, which is a mixture of amylose and amylopectin ${ }^{13,35}$. The differences between the TDA and DLS distributions are also likely due to the presence of aggregates. Due to their large size and small number, aggregates do not contribute significantly to the TDA signal, while they are detected by DLS. In addition, the aggregation phenomenon is particularly relevant for starches as the huge aggregates present in small proportion in starch solutions ( $R_{h}$ larger than $300 \mathrm{~nm}$ ) may influence significantly the outcome of the analysis of DLS data. Furthermore, it is known that aggregation is enhanced in the batch mode (as in our DLS experiments), as compared to in-flow measurements. Indeed, using a combination of AF4, MALS and/or online DLS ${ }^{13,35}$ previous studies found results closer to the TDA distributions

reported here. In particular, in references ${ }^{13,41}$, it was found that the $R_{h}$ distribution for normal maize starch was bimodal with a population of small objects $\left(R_{h}=6-20 \mathrm{~nm}\right)$ corresponding to amylose and another with $R_{h}=70-300 \mathrm{~nm}$ corresponding to amylopectin in agreement with TDA measurements. For amylose-free potato starch and cassava amylopectin, monomodal $R_{h}$ distributions ranging from $70 \mathrm{~nm}$ to 300 $\mathrm{nm}$ were obtained.

\subsection{Sensitivity of detection in TDA-BSI and TDA-UV-POD}

The (mass) sensitivity of detection of TDA-BSI and TDA-UV-POD (266 nm) were plotted against the molar mass of the sample in Figure 6. Sensitivity (in $y$-axis) was calculated from the front height (obtained by TDA in frontal mode) divided by the injected mass concentration of the sample. Higher molar mass (or higher degree of polymerization) leads to lower sensitivity for both TDA-UV-POD and TDA-BSI. In the 
case of $\mathrm{BSI}$ detection, the refractive index increment with the concentration is the main parameter that controls the sensitivity of detection; while for UV-POD the yields and kinetics of the photochemical reactions leading to the UV-absorbing species are the key parameters. Despite quite low sensitivity at high molar mass, we demonstrate in this work that the $R_{\mathrm{h}}$ distribution and average value can be derived from both detection modes, although UV-POD leads to lower LOD.

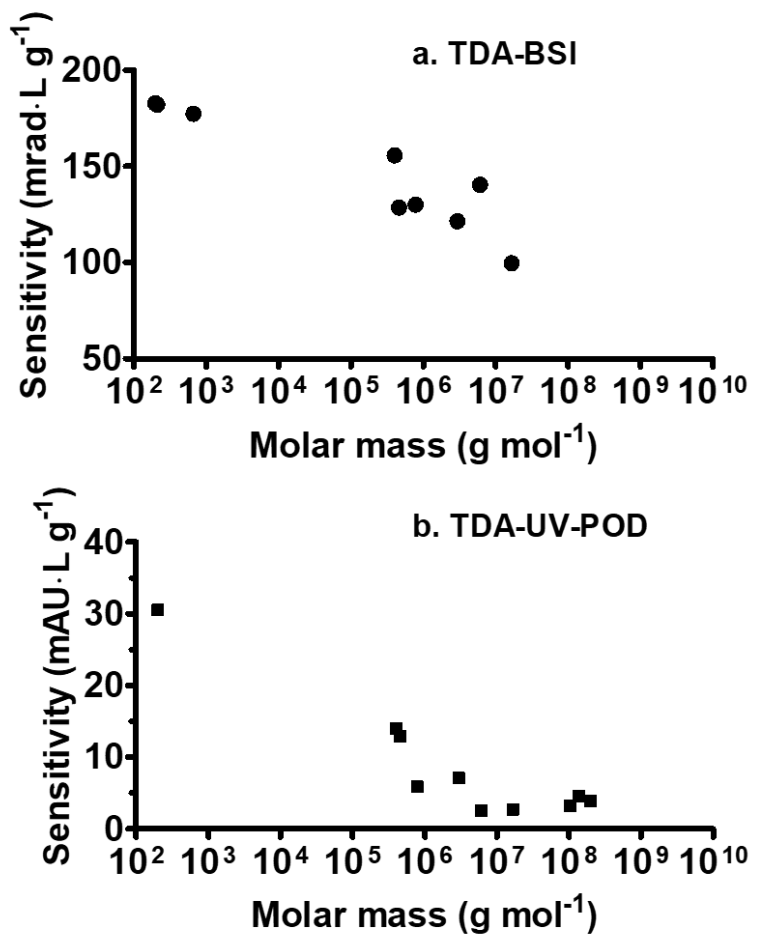

Figure 6. Detection sensitivity obtained by TDA-BSI (a) $\left(\bullet \mathrm{mrad} \cdot \mathrm{L} \mathrm{g}^{-1}\right)$ and by TDA-UV-POD at $266 \mathrm{~nm}$ (b) (匹, mAU. $\left.\mathrm{L} \mathrm{g}^{-1}\right)$ vs the molar mass of (poly)saccharides and starches. The (mass) sensitivity of detection of BSI and UV-POD detection modes decreased with the molar mass of the solute. Experimental conditions as in Table 2 using frontal injection of the sample.

\section{Conclusions}

In this work, we present the application to size characterization of polysaccharides and starches by batch DLS and TDA coupled with two different detection modes: backscattering interferometry (BSI) and UV-photooxidation 
detection (UV-POD). TDA-BSI employed water as eluent to perform the detection of all polysaccharide samples without any chemical treatment. TDA-UV-POD used strong alkaline eluents (130 mM NaOH or $1 \mathrm{M} \mathrm{KOH}$ for starches) to dissolve the polysaccharides/starches and to ensure the photochemical reaction. Hydrodynamic radius values obtained by TDA-BSI were in excellent agreement with those obtained by TDA-UV-POD $(266 \mathrm{~nm})$, provided that the injected concentration for UV-POD (266 nm) is carefully selected to remain in the linearity detection range. TDA results were compared to batch DLS performed in the same conditions. Overall, TDA and DLS are complementary techniques providing useful information on sample polydispersity. The present results also confirm that TDA analysis is less sensitive to aggregates than DLS measurements in batch mode ${ }^{54-55}$.

\section{Acknowledgements}

P.S. is thankful for the research project supported by Mahidol University (New Researcher grant: A9/2561).

\section{Supporting Information}

- Dynamic Zimm plots obtained for Cassava amylopectin, Normal maize starch and Amylose-free potato starch

- Taylorgrams obtained for glucose monohydrate and pullulan P400 by UV-POD using large plug injections

- Linearity and signal response of polysaccharides and starch obtained from TDAUV-POD in frontal mode at 214 and $266 \mathrm{~nm}$

- Taylorgrams of dextran T2000, pullulan P400, pullulan P800 and phytoglycogen obtained by TDA-UV-POD at $266 \mathrm{~nm}$ and TDA-BSI 


\section{References}

1. Ju, H.; Zhang, X.; Wang, J., Carbohydrate Detection Using Nanostructured Biosensing. In NanoBiosensing: Principles, Development and Application, Springer New York: New York, NY, 2011; pp 393-424.

2. Gortatowsky, C., Sugar and Other Carbohydrates in Carbonated Beverages. In Use of Sugars and Other Carbohydrates in Food Industry, American Chemical Society: 1955; Vol. 12, pp 70-74.

3. Schoch, T. J.; Elder, A. L., Starches in the Food Industry. In Use of Sugars and Other Carbohydrates in Food Industry, American Chemical Society: 1955; Vol. 12, pp 21-34.

4. Burd, A.; Huang, L., Chapter 11 - Carbohydrates and Cutaneous Wound Healing A2 - Garg, Hari G. In Carbohydrate Chemistry, Biology and Medical Applications, Cowman, M. K., Hales, C. A., Eds. Elsevier: Oxford, 2008; pp 253-274.

5. $\quad$ Avila, L. Z.; Gianolio, D. A.; Konowicz, P. A.; Philbrook, M.; Santos, M. R.; Miller, R. J., Chapter 15 - Drug Delivery and Medical Applications of Chemically Modified Hyaluronan A2 - Garg, Hari G. In Carbohydrate Chemistry, Biology and Medical Applications, Cowman, M. K., Hales, C. A., Eds. Elsevier: Oxford, 2008; pp 333-357.

6. Striegel, A. M.; Isenberg, S. L.; Côté, G. L. An SEC/MALS study of alternan degradation during size-exclusion chromatographic analysis. Anal. Bioanal. Chem. 2009, 394 (7), 1887-1893.

7. Gaborieau, M.; Gilbert, R. G.; Gray-Weale, A.; Hernandez, J. M.; Castignolles, P. Theory of Multiple-Detection Size-Exclusion Chromatography of Complex Branched Polymers. Macromol. Theory Simul. 2007, 16 (1), 13-28.

8. Gaborieau, M.; Nicolas, J.; Save, M.; Charleux, B.; Vairon, J.-P.; Gilbert, R. G.; Castignolles, P. Separation of complex branched polymers by size-exclusion chromatography probed with multiple detection. J. Chromatogr. A 2008, 1190 (1), 215-223.

9. Rolland-Sabaté, A., High-Performance Size-Exclusion Chromatography coupled with on-line Multi-angle Laser Light Scattering (HPSEC-MALLS). Bentham Science Publishers: 2017; p 92-136 (45).

10. Rolland-Sabaté, A., Battu, S., Bonfils, F., Chelbi, K., Martin, M., Field-Flow Fractionation (FFF). In Advances in Physicochemical Properties of Biopolymers (Part 1), Bentham Science Publishers: 2017.

11. Giddings, J. C. A New Separation Concept Based on a Coupling of Concentration and Flow Nonuniformities. Sep Sci Technol 1966, 1 (1), 123-125.

12. Messaud, F. A.; Sanderson, R. D.; Runyon, J. R.; Otte, T.; Pasch, H.; Williams, S. K. R. An overview on field-flow fractionation techniques and their applications in the separation and characterization of polymers. Prog Polym Sci 2009, 34 (4), 351-368.

13. Rolland-Sabaté, A.; Colonna, P.; Mendez-Montealvo, M. G.; Planchot, V. Branching Features of Amylopectins and Glycogen Determined by Asymmetrical Flow Field Flow Fractionation Coupled with Multiangle Laser Light Scattering. Biomacromolecules 2007, 8 (8), 2520-2532.

14. Yohannes, G.; Jussila, M.; Hartonen, K.; Riekkola, M. L. Asymmetrical flow field-flow fractionation technique for separation and characterization of biopolymers and bioparticles. J. Chromatogr. A 2011, 1218 (27), 4104-4116.

15. Otte, T.; Pasch, H.; Macko, T.; Brüll, R.; Stadler, F. J.; Kaschta, J.; Becker, F.; Buback, M. Characterization of branched ultrahigh molar mass polymers by asymmetrical flow field-flow fractionation and size exclusion chromatography. J. Chromatogr. A 2011, 1218 (27), 4257-4267.

16. Leeman, M. S., Matilda Ulmius; Nilsson, Lars. Practical Applications of Asymmetrical Flow Field-Flow Fractionation (AF4): A Review. LCGC Europe 2015, 28 (12), 10.

17. Renard, M. A. M. D., Advances in Physicochemical Properties of Biopolymers. Bentham Science Publishers: 2017; $\mathrm{p} 46$.

18. Renard, M. A. M. D., Advances in Physicochemical Properties of Biopolymers. Bentham Science Publishers: 2017; $\mathrm{p} 49$.

19. Volpi, N.; Maccari, F.; Linhardt, R. J. Capillary electrophoresis of complex natural polysaccharides. Electrophoresis 2008, 29 (15), 3095-3106. 
20. Rovio, S.; Yli-Kauhaluoma, J.; Siren, H. Determination of neutral carbohydrates by CZE with direct UV detection. Electrophoresis 2007, 28 (17), 3129-3135.

21. Rovio, S.; Simolin, H.; Koljonen, K.; Siren, H. Determination of monosaccharide composition in plant fiber materials by capillary zone electrophoresis. J. Chromatogr. A 2008, 1185 (1), 139-144.

22. Sarazin, C.; Delaunay, N.; Costanza, C.; Eudes, V.; Mallet, J.-M.; Gareil, P. New Avenue for Mid-UV-Range Detection of Underivatized Carbohydrates and Amino Acids in Capillary Electrophoresis. Anal. Chem. 2011, 83 (19), 7381-7387.

23. Oliver, J. D.; Gaborieau, M.; Hilder, E. F.; Castignolles, P. Simple and robust determination of monosaccharides in plant fibers in complex mixtures by capillary electrophoresis and high performance liquid chromatography. J. Chromatogr. A 2013, 1291, 179-186.

24. Schmid, T.; Himmelsbach, M.; Oliver, J. D.; Gaborieau, M.; Castignolles, P.; Buchberger, W. Investigation of photochemical reactions of saccharides during direct ultraviolet absorbance detection in capillary electrophoresis. J. Chromatogr. A 2015, 1388, 259-266.

25. Schmid, T.; Himmelsbach, M.; Buchberger, W. W. Investigation of photochemical reaction products of glucose formed during direct UV detection in CE. Electrophoresis 2016, 37 (7-8), 947-953. 26. Oliver, J. D.; Rosser, A. A.; Fellows, C. M.; Guillaneuf, Y.; Clement, J.-L.; Gaborieau, M.; Castignolles, P. Understanding and improving direct UV detection of monosaccharides and disaccharides in free solution capillary electrophoresis. Anal. Chim. Acta 2014, 809, 183-193.

27. Sarazin, C.; Delaunay, N.; Costanza, C.; Eudes, V.; Gareil, P. Application of a new capillary electrophoretic method for the determination of carbohydrates in forensic, pharmaceutical, and beverage samples. Talanta 2012, 99, 202-206.

28. Sarazin, C.; Delaunay, N.; Costanza, C.; Eudes, V.; Gareil, P. On the use of capillary electrophoresis for the determination of inorganic anions and cations, and carbohydrates in residues collected after a simulated suicide bombing attack. Talanta 2013, 103, 301-305.

29. Toutounji, M. R.; Van Leeuwen, M. P.; Oliver, J. D.; Shrestha, A. K.; Castignolles, P.; Gaborieau, M. Quantification of sugars in breakfast cereals using capillary electrophoresis. Carbohydr. Res. 2015, 408, 134-141.

30. Alinat, E.; Jemmali, S.; Delaunay, N.; Archer, X.; Gareil, P. Analysis of underivatized cellodextrin oligosaccharides by capillary electrophoresis with direct photochemically induced UVdetection. Electrophoresis 2015, 36 (14), 1555-1563.

31. Phoonthawee Saetear, J. C., Michael N. Kammer, Thomas J. Manuel, Jean-Philippe Biron, Darryl J. Bornhop, Hervé Cottet, Taylor Dispersion Analysis of polysaccharides using backscattering interferometry. Anal. Chem. 2017, 89, 6710-6718.

32. Rolland-Sabaté, A.; Colonna, P.; Potocki-Véronèse, G.; Monsan, P.; Planchot, V. Elongation and insolubilisation of $\alpha$-glucans by the action of Neisseria polysaccharea amylosucrase. $J$ Cereal Sci 2004, 40 (1), 17-30.

33. Bornhop, D. J.; Latham, J. C.; Kussrow, A.; Markov, D. A.; Jones, R. D.; Sørensen, H. S. FreeSolution, Label-Free Molecular Interactions Studied by Back-Scattering Interferometry. Science 2007, 317 (5845), 1732-1736.

34. Bornhop, D. J.; Kammer, M. N.; Kussrow, A.; Flowers, R. A.; Meiler, J. Origin and prediction of free-solution interaction studies performed label-free. Proc. Natl. Acad. Sci. U.S.A. 2016, 113 (12), E1595-E1604.

35. Chamieh, J.; Cottet, H. Comparison of single and double detection points Taylor Dispersion Analysis for monodisperse and polydisperse samples. J. Chromatogr. A 2012, 1241, 123-127.

36. Cipelletti, L.; Biron, J.-P.; Martin, M.; Cottet, H. Measuring Arbitrary Diffusion Coefficient Distributions of Nano-Objects by Taylor Dispersion Analysis. Anal. Chem. 2015, 87 (16), 8489-8496.

37. Koppel, D. E. Analysis of Macromolecular Polydispersity in Intensity Correlation Spectroscopy: The Method of Cumulants. J. Chem. Phys.1972, 57 (11), 4814-4820.

38. CONTIN package. http://s-provencher.com/pub/contin/

39. Provencher, S. W. A constrained regularization method for inverting data represented by linear algebraic or integral equations. Comput. Phys. Commun. 1982, 27 (3), 213-227. 
40. Roger, P.; Bello-Perez, L. A.; Colonna, P. Contribution of amylose and amylopectin to the light scattering behaviour of starches in aqueous solution. Polymer 1999, 40 (25), 6897-6909.

41. Rolland-Sabaté, A.; Guilois, S.; Jaillais, B.; Colonna, P. Molecular size and mass distributions of native starches using complementary separation methods: Asymmetrical Flow Field Flow Fractionation (A4F) and Hydrodynamic and Size Exclusion Chromatography (HDC-SEC). Anal. Bioanal. Chem. 2011, 399 (4), 1493-1505.

42. Cottet, H.; Biron, J.-P.; Martin, M. Taylor Dispersion Analysis of Mixtures. Anal. Chem. 2007, 79 (23), 9066-9073.

43. Cottet, H.; Biron, J.-P.; Martin, M. On the optimization of operating conditions for Taylor dispersion analysis of mixtures. Analyst 2014, 139 (14), 3552-3562.

44. Gidley, M. J.; Hanashiro, I.; Hani, N. M.; Hill, S. E.; Huber, A.; Jane, J.-L.; Liu, Q.; Morris, G. A.; Rolland-Sabaté, A.; Striegel, A. M.; Gilbert, R. G. Reliable measurements of the size distributions of starch molecules in solution: Current dilemmas and recommendations. Carbohydr. Polym. 2010, 79 (2), 255-261.

45. Latunde-Dada, S.; Bott, R.; Hampton, K.; Patel, J.; Leszczyszyn, O. I. Methodologies for the Taylor dispersion analysis for mixtures, aggregates and the mitigation of buffer mismatch effects. Anal. Methods 2015, 7 (24), 10312-10321.

46. Chamieh, J.; Leclercq, L.; Martin, M.; Slaoui, S.; Jensen, H.; Østergaard, J.; Cottet, H. Limits in Size of Taylor Dispersion Analysis: Representation of the Different Hydrodynamic Regimes and Application to the Size-Characterization of Cubosomes. Anal. Chem. 2017, 89 (24), 13487-13493.

47. Cottet, H.; Martin, M.; Papillaud, A.; Souaïd, E.; Collet, H.; Commeyras, A. Determination of Dendrigraft Poly-I-Lysine Diffusion Coefficients by Taylor Dispersion Analysis. Biomacromolecules 2007, 8 (10), 3235-3243.

48. Chamieh, J.; Jannin, V.; Demarne, F.; Cottet, H. Hydrodynamic size characterization of a selfemulsifying lipid pharmaceutical excipient by Taylor dispersion analysis with fluorescent detection. Int. J. Pharm. 2016, 513 (1), 262-269.

49. Chamieh, J.; Davanier, F.; Jannin, V.; Demarne, F.; Cottet, H. Size characterization of commercial micelles and microemulsions by Taylor dispersion analysis. Int. J. Pharm. 2015, 492 (1), 46-54.

50. Rolland-Sabaté, A.; Mendez-Montealvo, M. G.; Colonna, P.; Planchot, V. Online Determination of Structural Properties and Observation of Deviations from Power Law Behavior. Biomacromolecules 2008, 9 (7), 1719-1730.

51. Kerker, M., In The Scattering of Light and Other Electromagnetic Radiation. Academic Press: 1969.

52. Decaen, P.; Rolland-Sabaté, A.; Guilois, S.; Jury, V.; Allanic, N.; Colomines, G.; Lourdin, D.; Leroy, E. Choline chloride vs choline ionic liquids for starch thermoplasticization. Carbohydr. Polym. 2017, 177, 424-432.

53. Rolland-Sabaté, A.; Guilois, S.; Grimaud, F.; Lancelon-Pin, C.; Roussel, X.; Laguerre, S. ; Viks $\varnothing-$ Nielsen, A. ; Putaux, J.-L.; D'Hulst, C.; Potocki-Véronèse, G. ; Buléon, A. Characterization of hyperbranched glycopolymers produced in vitro using enzymes. Anal. Bioanal. Chem. 2014, 406, 1607-1618.

54. Hawe, A.; Hulse, W. L.; Jiskoot, W.; Forbes, R. T. Taylor Dispersion Analysis Compared to Dynamic Light Scattering for the Size Analysis of Therapeutic Peptides and Proteins and Their Aggregates. Pharm. Res. 2011, 28, 2302-2310.

55. Cottet, H.; Martin, M.; Papillaud, A.; Souaïd, E.; Collet, H.; Commeyras, A. Determination of Dendrigraft Poly-I-Lysine Diffusion Coefficients by Taylor Dispersion Analysis. Biomacromolecules 2007, 8, 3235-3243.

\section{For TOC only:}




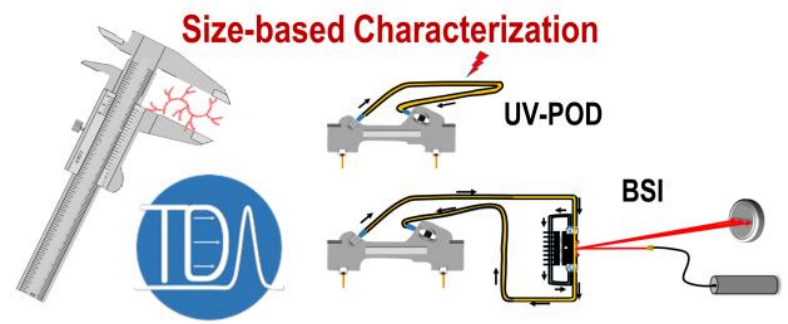

Page 33 / 33 